\title{
Analysis on the Influence of the Average Thickness of Sandstone in Overburden upon Mining Subsidence
}

\author{
Shijie Song ${ }^{1, a}$, Xiaoguang Zhao ${ }^{1, b}$, Mengdi $\mathrm{Gao}^{1}$, Wenjie $\mathrm{Nie}^{1}$ \\ ${ }^{1}$ College of Geology and Environment, Xi'an University of Science and Technology, Xi'an, China) \\ akkkbff@163.com, b13759991849@163.com
}

\begin{abstract}
Keywords: Sandstone Average Thickness; Mining Subsidence; Numerical Simulation; Yushen Coal Mining Area.
\end{abstract}

Abstract. The layered structure of overburden strata of coal measures is a remarkable geological characteristic of coal occurrence. The average thickness of sandstone is one of the key characteristics in the overburden layered structure, which can impact significantly the development of mining subsidence. Based on the geological characteristic of $2^{-2}$ coal seam and the representative drilling in the Yushen coal mining area and under conditions of the same depth and bedrock thickness (200m), 18 simplified models with different types of layered structure of overburden strata were constructed by taking the number of sandstone layers, their average thickness and the ratio of sand-shale as variables. On this basis, study was made on the influence rule of the sandstone average thickness upon the subsidence coefficient through the structural mechanics analysis and numerical simulation test. The results show that: first, based on analysis of structural mechanics, with the increase of the average thickness of sandstone, the maximum tensile stress and maximum deflection of overburden strata could decrease under the same load and elastic deformation so that the effect extent of same load on overburden strata can be decreased, and vice versa. Second, based on numerical simulation, the law that subsidence factor decreases while the average thickness of sandstone increases is discovered, and its change process includes two stages which are rapid decreased and tendency of stability. The fitted equation of the average thickness of sandstone and subsidence factor is established.

\section{Introduction}

Geological factors are the main factors that impact and control the development of mining subsidence. And this point has been generally acknowledged by scholars at home and abroad [1-2]. Currently, the related research about the effect of geological factors on mining subsidence focus on fold, fault[3], joint[4], tectonic stress[5], the ratio of rock and soil[6] and so on. But the layered structure of overburden strata of coal measures, as classical geological characteristic of coal occurrence, its influence on the occurrence and development process of mining subsidence has been neglected. Therefore, this paper constructed simplified models based on the geological characteristic of $2^{-2}$ coal seam and the representative drilling in the Yushen coal mining area. On this basis, the study was made on the influence rule of the sandstone average thickness upon the subsidence coefficient through the structural mechanics analysis and numerical simulation test. It hopes that the results can enrich and deepen the study on the effect of geological factors on mining subsidence.

\section{The geological occurrence characteristics of $2^{-2}$ coal}

Geological occurrence conditions. $2^{-2}$ coal is the main recoverable coal seam in Yushen coal mining area. Its thickness is $6.5 \mathrm{~m}$ in average. The buried depth of $2^{-2}$ coal is more than $200 \mathrm{~m}$ generally. The overburden main structure is "sand layer - soil layer - weathered layer -bedrock layer", and its distribution area of this type accounts for $65 \%$ in the whole area. The "sand layer" is modern eolian sand, and its thickness is 30m in average. The "soil layer" is under the "sand layer" and its thickness is $20 \mathrm{~m}$ in average. The " bedrock layer" is above $2^{-2}$ coal seam and its structure is interbedding structure of sandstone, siltstone and a small quantity of mudstone. The ratio of sand-shale is $60 \%-80 \%$ generally. The layer number of sandstone in overburden strata of $2^{-2}$ coal is between 3 to 35 layers. 
The characteristics of drilling. The data of representative drilling in the Yushen coal mining area show that: the layer number of sandstone in overburden strata of $2^{-2}$ coal is generally not more than 40 . The ratio of sand-shale is about $80 \%$. There are two sections obviously in the overburden strata of $2^{-2}$ coal. The structure of upper one is interbedding of "sandy mudstone-fine sandstone", and the structure of lower one is interbedding of "siltstone-fine sandstone". The layer number of sandy mudstone is 4 generally and its average thickness is $10 \mathrm{~m}$ above. The sum of layers number of siltstone and fine sandstone are the most part of the bedrock layer and their average thickness is similar.

\section{The model of overburden strata of $2^{-2}$ coal}

Based on the geological characteristic of $2^{-2}$ coal seam and the representative drilling in the Yushen coal mining area, the framework model of overburden was designed firstly. Then, the models with different types of layered structure of overburden strata were constructed by taking the number of sandstone layers, their average thickness and the ratio of sand-shale as variables.

The framework model of overburden. The framework model of overburden was designed as "sand layer - laterite layer - bedrock layer- $2^{-2}$ coal seam-baseboard". Basic geometric parameter of framework was set that: the buried depth of $2^{-2}$ coal was $250 \mathrm{~m}$ and its thickness was $5 \mathrm{~m}$; the thickness of sand layer, laterite layer and bedrock layer was $30 \mathrm{~m}, 20 \mathrm{~m}$ and $200 \mathrm{~m}$ respectively.

The type of structure in bedrock. According to the characteristics of representative drilling, the bedrock was divided into two parts, the structure of upper part was interbedding of fine sandstone and mudstone, and the structure of lower part was interbedding of fine sandstone and siltstone. Referring to the actual layered structure of drilling, the upper part was divided into 4 cycles, and the lower part was divided into different cycles according to the need.

In the model, the number of sandstone layers, their average thickness and the ratio of sand-shale were valued according to the geological occurrence characteristic of $2^{-2}$ coal. The value of sandstone layers were set as $6,8,10,20,30$, and 40 layers respectively and the number of mudstone layer was fixed as 4; the ratio of sand-shale were set as 6:4, 7:3, and 8:2 respectively; the thickness values of fine sandstone, siltstone and mudstone could be set with the number of sandstone and the ratio of sand-shale under the condition of same bedrock thickness $(200 \mathrm{~m})$. It is worth to explain that the thickness of siltstone and fine sandstone were set same because their average thickness was similar. Therefore, 18 simplified models with different types of layered structure of overburden strata were constructed. The types and geometric parameters of models are shown in Table 1.

Table.1 The types and geometric parameters of layered structure in the overburden (the total thickness of bedrock is $200 \mathrm{~m}$ )

\begin{tabular}{|c|c|c|c|c|c|c|c|}
\hline \multirow[t]{2}{*}{$\begin{array}{c}\text { Sand-shale } \\
\text { ratio }\end{array}$} & \multirow[t]{2}{*}{ Type } & \multirow[t]{2}{*}{$\begin{array}{l}\text { Sand layer } \\
\text { (layer } \\
\text { /thickness) }\end{array}$} & \multirow[t]{2}{*}{$\begin{array}{l}\text { Laterite layer } \\
\text { (layer } \\
\text { /thickness) }\end{array}$} & \multicolumn{2}{|c|}{$\begin{array}{c}\text { Interbedding of fine sandstone } \\
\text { and mudstone } \\
\text { (layer /thickness) }\end{array}$} & \multicolumn{2}{|c|}{$\begin{array}{c}\text { Interbedding of fine sandstone } \\
\text { and siltstone } \\
\text { (layer /thickness) }\end{array}$} \\
\hline & & & & Fine sandstone & Mudstone & Fine sandstone & Siltstone \\
\hline \multirow{6}{*}{$6: 4$} & A1 & $1 / 30 \mathrm{~m}$ & $1 / 20 \mathrm{~m}$ & $4 / 20 \mathrm{~m}$ & $4 / 20 \mathrm{~m}$ & $1 / 20 \mathrm{~m}$ & $1 / 20 \mathrm{~m}$ \\
\hline & $\mathrm{A} 2$ & $1 / 30 \mathrm{~m}$ & $1 / 20 \mathrm{~m}$ & $4 / 15 \mathrm{~m}$ & $4 / 20 \mathrm{~m}$ & $2 / 15 \mathrm{~m}$ & $2 / 15 m$ \\
\hline & A3 & $1 / 30 \mathrm{~m}$ & $1 / 20 \mathrm{~m}$ & $4 / 12 \mathrm{~m}$ & $4 / 20 \mathrm{~m}$ & $3 / 12 \mathrm{~m}$ & $3 / 12 \mathrm{~m}$ \\
\hline & A4 & $1 / 30 \mathrm{~m}$ & $1 / 20 \mathrm{~m}$ & $4 / 6 \mathrm{~m}$ & $4 / 20 \mathrm{~m}$ & $8 / 6 \mathrm{~m}$ & $8 / 6 \mathrm{~m}$ \\
\hline & A5 & $1 / 30 \mathrm{~m}$ & $1 / 20 \mathrm{~m}$ & $4 / 4 \mathrm{~m}$ & $4 / 20 \mathrm{~m}$ & $13 / 4 m$ & $13 / 4 m$ \\
\hline & A6 & $1 / 30 \mathrm{~m}$ & $1 / 20 \mathrm{~m}$ & $4 / 3 \mathrm{~m}$ & $4 / 20 \mathrm{~m}$ & $18 / 3 m$ & $18 / 3 \mathrm{~m}$ \\
\hline \multirow{6}{*}{$7: 3$} & B1 & $1 / 30 \mathrm{~m}$ & $1 / 20 \mathrm{~m}$ & $4 / 23 m$ & $4 / 15 \mathrm{~m}$ & $1 / 23 \mathrm{~m}$ & $1 / 23 \mathrm{~m}$ \\
\hline & B2 & $1 / 30 \mathrm{~m}$ & $1 / 20 \mathrm{~m}$ & $4 / 17.5 \mathrm{~m}$ & $4 / 15 \mathrm{~m}$ & $2 / 17.5 \mathrm{~m}$ & $2 / 17.5 \mathrm{~m}$ \\
\hline & B3 & $1 / 30 \mathrm{~m}$ & $1 / 20 \mathrm{~m}$ & 4/14m & $4 / 15 \mathrm{~m}$ & 3/14m & 3/14m \\
\hline & B4 & $1 / 30 \mathrm{~m}$ & $1 / 20 \mathrm{~m}$ & 4/7m & $4 / 15 \mathrm{~m}$ & 8/7m & 8/7m \\
\hline & B5 & $1 / 30 \mathrm{~m}$ & $1 / 20 \mathrm{~m}$ & $4 / 4.7 \mathrm{~m}$ & $4 / 15 \mathrm{~m}$ & $13 / 4.7 \mathrm{~m}$ & $13 / 4.7 \mathrm{~m}$ \\
\hline & B6 & $1 / 30 \mathrm{~m}$ & $1 / 20 \mathrm{~m}$ & $4 / 3.5 \mathrm{~m}$ & $4 / 15 m$ & $18 / 3.5 \mathrm{~m}$ & $18 / 3.5 \mathrm{~m}$ \\
\hline \multirow{6}{*}{$8: 2$} & C1 & $1 / 30 \mathrm{~m}$ & $1 / 20 \mathrm{~m}$ & $4 / 27 \mathrm{~m}$ & $4 / 10 \mathrm{~m}$ & $1 / 27 \mathrm{~m}$ & $1 / 27 \mathrm{~m}$ \\
\hline & $\mathrm{C} 2$ & $1 / 30 \mathrm{~m}$ & $1 / 20 \mathrm{~m}$ & $4 / 20 \mathrm{~m}$ & $4 / 10 \mathrm{~m}$ & $2 / 20 \mathrm{~m}$ & $2 / 20 \mathrm{~m}$ \\
\hline & C3 & $1 / 30 \mathrm{~m}$ & $1 / 20 \mathrm{~m}$ & $4 / 16 \mathrm{~m}$ & $4 / 10 \mathrm{~m}$ & $3 / 16 \mathrm{~m}$ & $3 / 16 \mathrm{~m}$ \\
\hline & $\mathrm{C} 4$ & $1 / 30 \mathrm{~m}$ & $1 / 20 \mathrm{~m}$ & 4/8m & $4 / 10 \mathrm{~m}$ & 8/8m & 8/8m \\
\hline & C5 & $1 / 30 \mathrm{~m}$ & $1 / 20 \mathrm{~m}$ & $4 / 5 \mathrm{~m}$ & $4 / 10 \mathrm{~m}$ & $13 / 5 \mathrm{~m}$ & $13 / 5 \mathrm{~m}$ \\
\hline & C6 & $1 / 30 \mathrm{~m}$ & $1 / 20 \mathrm{~m}$ & $4 / 4 \mathrm{~m}$ & $4 / 10 \mathrm{~m}$ & $18 / 4 \mathrm{~m}$ & $18 / 4 \mathrm{~m}$ \\
\hline
\end{tabular}




\section{The effect of the sandstone average thickness on mining subsidence}

At the beginning of underground mining, the bedrock in the overburden strata of coal measures is in continuous state approximately so that its deformation can be deemed elastic deformation. Therefore, under this condition, the bedrock can be similar to the structure of clamped-clamped beam. Under the same span $l$, the study was made on the effect of the sandstone average thickness on mining subsidence and overburden strata with calculating the maximum tensile stress and maximum deflection caused by the dead weight of overburden in different type models.

The physical and mechanical parameters of strata (soil layer) in the model. According to the data of drilling in Yushen coal mining area, the physical and mechanical parameters of strata (soil layer) were given.

Results and discussion. According to the structural mechanics principle of clamped-clamped beam and composite beam, under the same span $l$, the maximum tensile stress and maximum deflection (when in the elastic state) caused by the dead weight of overburden in 18 different type models were calculated. The results were shown in Table 2.

Table. 2 The calculation results of maximum tensile stress and maximum deflection

\begin{tabular}{ccccccc}
\hline \multirow{2}{*}{ Model code } & \multicolumn{3}{c}{ Model load $(\mathrm{kN} / \mathrm{m})$} & \multirow{2}{*}{ Maximum tensile stress $\left(\mathrm{kN} / \mathrm{m}^{2}\right)$} & \multirow{2}{*}{ Maximum deflection $\left(10^{-10} \mathrm{~m}\right)$} \\
\cline { 2 - 5 } & $\mathrm{Q}_{\text {sand }}$ & $\mathrm{Q}_{\text {soil }}$ & $\mathrm{Q}_{\text {Fs-m }}$ & $\mathrm{Q}_{\text {Fs-s }}$ & & $3.87 * l^{4}$ \\
A1 & 516 & 372 & 3872.0 & 972.0 & $0.90 * l^{2}$ & $4.59 * l^{4}$ \\
A2 & 516 & 372 & 3390.0 & 1458.0 & $0.80 * l^{2}$ & $5.98 * l^{4}$ \\
A3 & 516 & 372 & 3100.8 & 1749.6 & $0.83 * l^{2}$ & $17.9 * l^{4}$ \\
A4 & 516 & 372 & 2522.4 & 2332.8 & $1.25 * l^{2}$ & $37.3 * l^{4}$ \\
A5 & 516 & 372 & 2329.6 & 2527.2 & $1.73 * l^{2}$ & $63.8 * l^{4}$ \\
A6 & 516 & 372 & 2233.2 & 2624.4 & $2.22 * l^{2}$ & $2.52 * l^{4}$ \\
B1 & 516 & 372 & 3675.2 & 1117.8 & $0.67 * l^{2}$ & $2.89 * l^{4}$ \\
B2 & 516 & 372 & 3145.2 & 1701.0 & $0.59 * l^{2}$ & $3.76 * l^{4}$ \\
B3 & 516 & 372 & 2807.6 & 2041.2 & $0.61 * l^{2}$ & $11.3 * l^{4}$ \\
B4 & 516 & 372 & 2132.8 & 2721.6 & $0.92 * l^{2}$ & $23.1 * l^{4}$ \\
B5 & 516 & 372 & 1911.2 & 2969.2 & $1.26 * l^{2}$ & $40.2 * l^{4}$ \\
B6 & 516 & 372 & 1795.2 & 3061.8 & $1.63 * l^{2}$ & $1.58^{*} l^{4}$ \\
C1 & 516 & 372 & 3574.8 & 1312.2 & $0.50 * l^{2}$ & $1.93 * l^{4}$ \\
C2 & 516 & 372 & 2900.0 & 1944.0 & $0.45 * l^{2}$ & $2.52 * l^{4}$ \\
C3 & 516 & 372 & 2514.4 & 2332.8 & $0.47 * l^{2}$ & $7.57 * l^{4}$ \\
C4 & 516 & 372 & 1743.2 & 3110.4 & $0.70 * l^{2}$ & $18.3^{2} l^{4}$ \\
C5 & 516 & 372 & 1454.0 & 3159.0 & $1.06 * l^{2}$ & $26.9 * l^{4}$ \\
C6 & 516 & 372 & 1357.6 & 3499.2 & $1.25 * l^{2}$ & Q
\end{tabular}

PS: Q Fs-m means the load caused by interbedding of fine sandstone and mudstone; $\mathrm{Q}_{\mathrm{Fs}-\mathrm{s}}$ means the load caused by interbedding of fine sandstone and siltstone; When all the model were calculating, $b$ was 1 ; $l$ was spanned, $\mathrm{m}$.

According to Table 1 and Table 2, two kinds of corresponding relation were established. The one is that corresponding relation between the sandstone average thickness and maximum tensile stress; another is that corresponding relation between the sandstone average thickness and maximum deflection. The results were shown in Fig.1 and Fig. 2.

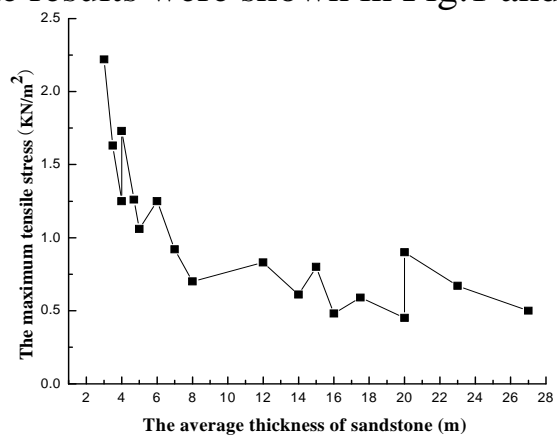

Fig.1 The corresponding relationship between sandstone average thickness and the maximum tensile stress $(b=1, l=1)$

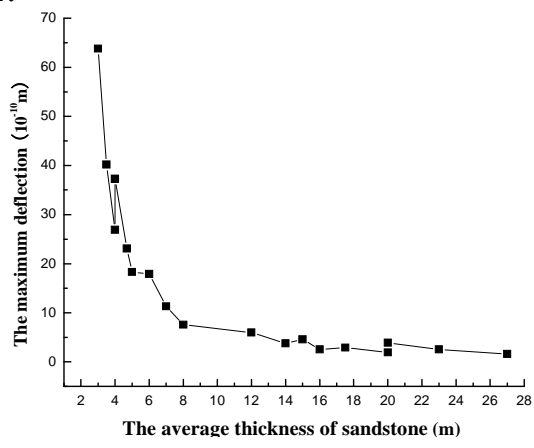

Fig.2 The corresponding relationship between sandstone average thickness and the maximum deflection $(b=1, l=1)$ 
By Fig.1, with the increase of sandstone average thickness, the maximum tensile stress in the overburden presents the change trend of decrease. And there are two stages in this trend obviously.

Stage 1: Decrease rapidly. When the average thickness of sandstone was less than $8 \mathrm{~m}$, the maximum tensile stress in the overburden rapidly decreased with the increase of the average thickness of sandstone. For example, the maximum tensile stress $\left(0.7 \mathrm{KN} / \mathrm{m}^{2}\right)$ with the average thickness of $8 \mathrm{~m}$ is $32 \%$ of the maximum tensile stress $\left(2.22 \mathrm{KN} / \mathrm{m}^{2}\right)$ with the average thickness of $3 \mathrm{~m}$.

Stage 2: Waving decrease. When the average thickness of sandstone was more than $8 \mathrm{~m}$, the maximum tensile stress in the overburden undulant decreased slowly with the increase of the average thickness of sandstone.

Based on EXP3 mathematical model, the quantitative relationship between the average thickness of sandstone and the maximum tension stress was given. It is shown as Formula (1).

$$
y=0.514 \cdot e^{\frac{3.832}{x-0.347}} \quad R^{2}=0.8989 \quad \mathrm{Chi}^{2} / \mathrm{DoF}=0.02722
$$

By Fig.2, with the increase of sandstone average thickness, the maximum deflection in the overburden presents the change trend of decrease. And there are two stages in this trend obviously.

Stage 1: Decrease rapidly. When the average thickness of sandstone was less than $8 \mathrm{~m}$, the maximum deflection in the overburden rapidly decreased with the increase of the average thickness of sandstone. For example, the maximum deflection $\left(7.57 \times 10^{-10} \mathrm{~m}\right)$ with the average thickness of $8 \mathrm{~m}$ is $12 \%$ of the maximum deflection $\left(63.8 \times 10^{-10} \mathrm{~m}\right)$ with the average thickness of $3 \mathrm{~m}$.

Stage 2: Decrease slowly. When the average thickness of sandstone was more than $8 \mathrm{~m}$, the maximum deflection in the overburden decreased slowly with the increase of the average thickness of sandstone.

Based on EXP3 mathematical model, the quantitative relationship between the average thickness of sandstone and the maximum deflection stress was given. It is shown as Formula (2).

$$
y=1.405 \cdot e^{\frac{17.443}{x+1.594}} \quad R^{2}=0.982 \quad C h i^{2} / D o F=6.03147
$$

\section{The numerical simulation test and analysis}

\section{Numerical models.}

(1) Geometry size of models. In the model named A3, there were 16 layers strata (or soil layer) in the overburden of $2^{-2}$ coal whose thickness was $5 \mathrm{~m}$. The length of face was $250 \mathrm{~m}$. The other types of model were the same as A3 in length, height, width and so on. The number and thickness of strata (or soil layer) were set up according to Table 1.

(2) Boundary conditions of models. The boundaries in the left, right, front and back of the model were set unilateral constraint; the boundaries in the bottom of the model were multiconstraint; the boundaries on the surface of the model were free.

(3) Physical and mechanical parameters of models. The physical and mechanical parameters of coal seam and (or soil layer) in the models can be set up according to the data of drilling in Yushen coal mining area.

Results and analysis. According to the test results of the numerical simulation with 18 models, the corresponding relation between the average thickness of sandstone and subsidence coefficient was given and shown in Fig. 3. 


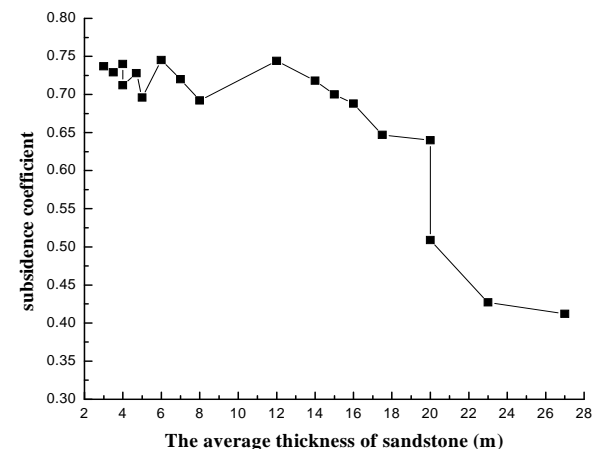

Fig.3 The corresponding relationship between the average thickness of sandstone and subsidence coefficient

By Fig.3, with the increase of sandstone average thickness, the subsidence coefficient presents the change trend of decrease.

When the average thickness of sandstone was less than $15 \mathrm{~m}$, the subsidence coefficient was more than 0.7 generally; when the average thickness of sandstone was between $15 \mathrm{~m}$ and $23 \mathrm{~m}$, the subsidence coefficient rapidly decreased with the increase of the average thickness of sandstone and its minimum was 0.4 ; when the average thickness of sandstone was more than $23 \mathrm{~m}$, the subsidence coefficient decreased very slowly. Based on Dose Resp mathematical model, the quantitative relationship between the average thickness of sandstone and subsidence coefficient was given. It is shown as Formula (3).

$$
q=0.396+\frac{0.328}{1+10^{-0.247 \cdot(20.082-x)}} \quad R^{2}=0.9306 \quad \text { Chi }^{2} / \mathrm{DoF}=0.00094
$$

\section{Conclusions}

(1) With the increase of sandstone average thickness, the maximum tensile stress and the maximum deflection of the overburden present the change trend of decrease. The change process of the maximum tensile stress included two stages, the first one was decrease rapidly stage, and the second one was waving decrease stage. The change process of the maximum deflection included two stages, the first one was decrease rapidly stage, and another one was decrease slowly stage. Therefore, under the same load and elastic deformation, the maximum tensile stress and maximum deflection of overburden could decrease with the increase of the average thickness of sandstone so that the effect extent of same load on overburden can be decreased, and vice versa.

(2) Based on numerical simulation, the law that subsidence factor decreases while the average thickness of sandstone increases is discovered, and its change process includes two stages which are rapid decreased and tendency of stability. The fitted equation of the average thickness of sandstone and subsidence factor is established.

\section{Acknowledgments}

Financial support for this work is provided by the National Science Foundation for Young Scientists of China (No.41402308), Scientific Research Program Funded by Shaanxi Provincial Education Department (No.14JK1466), Cultivation Foundation of Xi'an University of Science and Technology (No.201308), Scientific Research Foundation for Doctors of Xi'an University of Science and Technology (No.2014QDJ006), all of which are gratefully acknowledged.

\section{References}

[1]Donnelly, L. J., Delacruz, H., Asmar, I. O., et.al. Engineering Geology, Vol. 59 (2001),p:103-114. [2]Xiaoguang Zhao,Shijie Song,Yuanyuan Guan .China Coal, Vol. 36 (2010),p:124-127.(In Chinese) 
[3]Haijun Zhao, Fengshan Ma, Guoqing Li.Chinese Journal of Geotechnical Engineering, Vol.30(2008), p: 1372-1375.(In Chinese).

[4]Xun Guo, Junwu Dai. Journal of Liaoning Technology University, Vol.25(2006),p:852-854.(In Chinese).

[5]Yucheng Xia, Tongwen Lei. Journal of Liaoning Engineering Technology University, Vol.25 (2006),p: 527-529.(In Chinese).

[6] Shijie Song, Xiaoguang Zhao, Shuangming Wang, et al. China Coal, Vol.41 (2015), p:63-67.(In Chinese). 